\title{
CoolabBici: sistema de apoio para sensibilização e promoção do uso da bicicleta como transporte
}

\author{
Gheysa Caroline Prado
}

gheysa.prado@ufpr.br

\section{Kamila Elisabeth do Espírito Santo}

Almeida Coelho da Cruz

kamilaelisabeth@gmail.com

Marina Caus dos Santos

causmarina@gmail.com

\section{Carolina Teixeira dos Santos}

carolina.teixeira.santos@gmail.com

\section{Letícia Zem Messias}

leticia.z.e.m21@gmail.com

\section{Resumo}

0 projeto de extensão 'Sensibilização para o Uso da Bicicleta como Modal de Transporte pela Comunidade UFPR' busca promover a mudança de hábitos na comunidade interna e externa à UFPR através do incentivo do uso da bicicleta como transporte. Para isso, o projeto realiza diversas ações educativas e de interação junto à comunidade e é o responsável a criação de um sistema de compartilhamento de bicicletas recuperadas, o CoolabBici. Este artigo tem como objetivo apresentar e detalhar o processo de criação e funcionamento do CoolabBici, que foi desenvolvido utilizando princípios do Design Thinking de Serviços. Os resultados apontam para o funcionamento adequado do sistema e potencial de replicação e expansão.

\section{Palavras-chave}

Mobilidade urbana; design thinking; bicicleta. 


\section{Introdução}

O crescimento exponencial da população mundial e a mudança de perfil do estilo de vida das pessoas ao longo do último século, passando de um perfil majoritariamente rural e habitando em áreas de menor densidade, para urbano adensado, ocasionaram o crescimento desordenado das cidades, com consequências negativas em diversas áreas que impactam na qualidade de vida nestes locais. Uma destas áreas é a de mobilidade urbana, que especificamente no contexto brasileiro, embasado no modelo estado-unidense, foi afetada também pelas políticas públicas direcionadas ao rodoviarismo em detrimento dos demais meios de transporte.

A mobilidade urbana planejada tendo como base os veículos automotores, e com robustos incentivos ao transporte individual, tem se mostrado ineficiente ao longo dos anos, seja por seus impactos ambientais, econômicos ou sociais. Dos impactos ambientais, o mais conhecido é a emissão de gases de efeito estufa provenientes de combustíveis fósseis e não renováveis, mas também há a poluição sonora e a degradação da paisagem urbana, com redução da permeabilidade do solo por conta do excesso de pavimentação para acomodar tais veículos (OPAS, 2019). Os impactos econômicos e sociais deste modelo vão desde o desperdício de tempo produtivo das pessoas em congestionamentos ao grande número de acidentes que, no Brasil, causam aproximadamente 40 mil mortes todos os anos (RAMALHO, 2018; VIAS SEGURAS, 2020).

Esse panorama é generalizável nacionalmente a cidades de médio e grande porte, nas quais os sistemas de transporte coletivo costumam deixar muito a desejar - o número de viagens realizadas em transporte público e veículos particulares é semelhante, mas cada viagem de carro consome o triplo de energia das realizadas em transporte coletivo - e há pouco incentivo a formas ativas de mobilidade, mesmo para pequenas e médias distâncias (RECK NETO, 2018). De acordo com a Organização Mundial da Saúde, a qualidade da mobilidade a que se tem acesso tem efeitos na qualidade do sono, estresse, obesidade, sedentarismo e outros problemas de saúde (ITDP, 2016).

Especificamente na cidade de Curitiba, que tem aproximadamente 2 milhões de habitantes (IBGE, 2019), o transporte individual motorizado é o modal mais utilizado, com 49,2\% da distribuição modal. 0 transporte coletivo é responsável por 23,8\% dos deslocamentos e os modais ativos representam $23,5 \%$ - sendo $21,7 \%$ a pé e $1,8 \%$ em bicicleta. Os demais meios, motocicleta, táxi e outros, dividem os 3,5\% restantes (IPPUC, 2017). Além disso, a cidade também possui alta taxa de motorização, de 1,2 veículos por habitante (IBGE, 2019).

Neste cenário, no ano de 2015 as maiores universidades de Curitiba - UFPR, UTFPR, PUCPR e UP -, em parceria com a Universidade de Twente, da Holanda, realizaram uma pesquisa com o objetivo de identificar os padrões de deslocamento dos membros destas comunidades 
acadêmicas de e para as universidades. Foram coletadas também informações sobre as possíveis barreiras e motivadores ao uso da bicicleta e do sistema coletivo como meios de transporte pelo grupo da comunidade universitária.

Especificamente sobre a comunidade da UFPR, os dados apontam para uma prevalência do uso do ônibus como meio de transporte entre os respondentes $(44,86 \%)$, mas tendo o automóvel como segundo modal mais utilizado (34,16\%). Entretanto, há consideráveis diferenças entre os campi estudados. Nos campi Centro Politécnico e Botânico o uso do carro é muito maior do que no campus Reitoria, por exemplo, e há evidências que apontam que essa diferença se deve ao oferecimento de estacionamentos amplos e gratuitos naqueles campi, incentivando e facilitando o uso do carro. Outros fatores podem estar relacionados à facilidade de acesso ao campus Reitoria, que fica na área central da cidade, sendo atendido por várias linhas de ônibus, estrutura cicloviária no entorno e à proximidade com as residências estudantis (UFPR, 2016).

A partir destes apontamentos, reflete-se sobre impacto gerado pela UFPR no trânsito curitibano, considerada polo gerador de tráfego ${ }^{1}$ devido à movimentação de aproximadamente 34.000 pessoas que fazem parte desta comunidade na cidade, entre docentes, técnicosadministrativos e discentes. Consciente de seu papel de promotora de impacto e transformação social, houve a criação do projeto extensionista chamado 'Sensibilização para o Uso da Bicicleta como Modal de Transporte pela Comunidade UFPR', que faz parte do programa de extensão Ciclovida UFPR e cujo objetivo é transformar a UFPR em núcleo irradiador de uma cultura de mobilidade urbana mais saudável e sustentável (dos Santos et al., 2018).

Este projeto extensionista busca, por meio da interação dialógica e com parcerias marcadas pela troca de saberes, incentivar a mobilidade urbana ativa e sustentável, caracterizada como política urbana que visa planejar de forma integrada a interdependência entre as esferas econômica e socioambiental. Para atingi-la, procura promover que os deslocamentos necessários sejam feitos com menor gasto energético e impacto ambiental possíveis, de modo a serem mais socialmente inclusivos, por meio de modais ativos - onde o modal depende da propulsão humana e o cidadão é agente ativo no trânsito (Ministério das Cidades, 2017).

A bicicleta foi escolhida como modal a ser incentivado pois foi eleita como o transporte ecologicamente mais sustentável do planeta pela Organização das Nações Unidas em 2010, e apresenta uma série de vantagens, entre as quais a revalorização e aproveitamento do espaço urbano e melhora nas relações humanas; promoção da saúde; baixo custo de manutenção, não

\footnotetext{
1 "Os polos geradores de tráfego são empreendimentos de grande porte que atraem ou produzem grande número de viagens, causando reflexos negativos na circulação viária em seu entorno imediato e, em certos casos, prejudicando a acessibilidade de toda a região, além de agravar as condições de segurança de veículos e pedestres." (DENATRAN, 2001 p. 8)
} 
utilização de combustível emissor de gases poluentes e a participação do cidadão como agente ativo no trânsito (SALLES, 2010; ITDP, 2019).

Deste modo, as formas de incentivo oferecidas pelo projeto são a realização de oficinas de mecânica básica e de conforto ao pedalar na cidade abertas à toda a comunidade; apoio à criação e elaboração de materiais informativos sobre pedalar na cidade; coleta de doações de equipamentos de segurança como refletivos, buzinas e retrovisores; realização de eventos públicos para orientação de ciclistas e distribuição de materiais informativos e equipamentos angariados; e, por fim, o resgate e recuperação de bicicletas abandonadas nos campi da universidade ou recebidas de doação que permitiram a criação de um sistema colaborativo de compartilhamento de bicicletas para a comunidade interna da UFPR, o CoolabBici, direcionado aos membros da comunidade interna da UFPR e tema deste artigo.

O projeto é desenvolvido no âmbito do Departamento de Design, evidenciando o princípio de interdisciplinaridade e interprofissionalidade de suas ações, propiciando às pessoas envolvidas - estudantes, docentes e técnicos-administrativos de diversas áreas e departamentos da universidade - uma visão holística da mobilidade urbana ativa e sustentável. Além disso, é possível apontar o caráter indissociável do ensino, pesquisa e extensão quando os e as estudantes envolvidas podem contribuir ativamente no desenvolvimento, planejamento e promoção das ações realizadas, identificando necessidades, pesquisando e apresentando soluções práticas com base nos conhecimentos adquiridos em sua formação, mas também oriundos de suas participações no próprio projeto, pelo qual é possível destacar o impacto em suas formações com a ampliação do universo de referência e contato com uma questão tão contemporânea e que afeta a vida de todas as pessoas quanto o problema da mobilidade nas cidades.

\section{Objetivos}

Neste tópico são apresentados os objetivos do presente artigo, compostos por um objetivo geral e demais objetivos específicos.

O objetivo geral do presente artigo é:

- Apresentar e detalhar o processo de criação e funcionamento do CoolabBici, desenvolvido no âmbito do projeto utilizando princípios do Design Thinking de Serviços, em parceria com uma bicicletaria da cidade, associação local de ciclistas e uma ONG.

Para atingir este objetivo, são apontados os seguintes objetivos específicos: 
- Apresentar o contexto de surgimento e elaboração do sistema de empréstimo dentro do projeto;

- Descrever os princípios do design thinking de serviços utilizados para a estruturação e funcionamento do sistema;

- Apresentar os resultados gerais obtidos pelo sistema de empréstimo desde o início da operação, no segundo semestre de 2017 até o período de férias 2019/2020.

\section{Metodologia}

O projeto de extensão "Sensibilização para o uso da bicicleta como modal de transporte na comunidade UFPR" teve início em maio de 2017 e tem como objetivo incentivar e promover o uso da bicicleta como meio de transporte por meio da sensibilização da comunidade para o tema. Para isso, o projeto desenvolve diversas ações abertas e direcionadas à comunidade e produção de materiais, conforme mencionado anteriormente, entre as quais a criação de um sistema colaborativo de compartilhamento de bicicletas para a comunidade interna da UFPR, o CoolabBici, que é o tema do presente trabalho.

A ideia para a criação e desenvolvimento desta ação do projeto surgiu a partir de uma demanda interna da própria universidade, que havia localizado e resgatado uma série de bicicletas abandonadas nos paraciclos e bicicletários dos campi da UFPR em Curitiba. A partir do resgate e os devidos trâmites, o programa de extensão Ciclovida foi procurado para dar destinação às mesmas.

Para o estabelecimento do sistema colaborativo foram realizadas parcerias com a iniciativa privada e organizações da sociedade civil organizada sendo: uma bicicletaria - a Bicicletaria Cultural -, a associação de ciclistas da cidade de Curitiba e região - a Ciclolguaçu -, e uma organização não governamental cujas ações são direcionadas ao fomento do uso da bicicleta nas cidades - a Bike Anjo. Além disso, o modelo teórico do funcionamento do projeto e suas estratégias internas foram desenvolvidas com a utilização de ferramentas e princípios do design thinking de serviços (STICKDORN e SCHNEIDER, 2014), conforme Figura 1 (a seguir) para a promoção de comportamentos sustentáveis (TANG e BHAMRA, 2012), como produto da tese de doutorado da professora coordenadora do projeto (PRADO, 2019). 


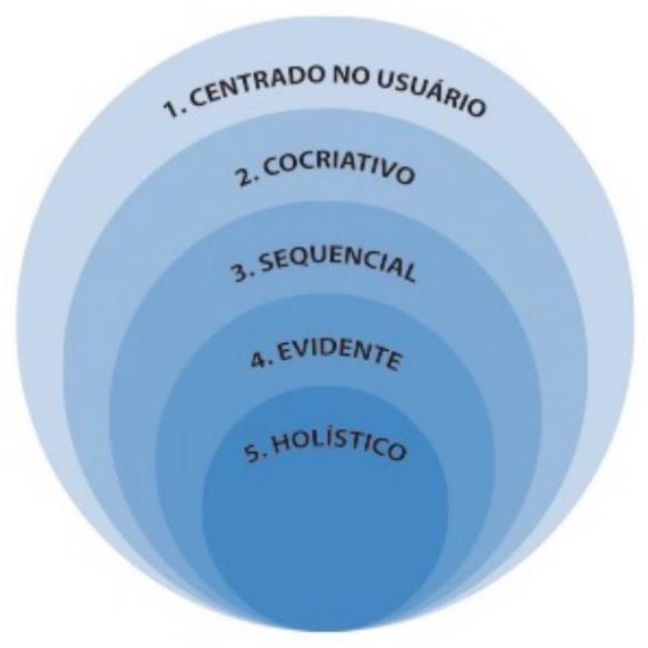

Figura 1: Princípios do Design Thinking de Serviços. Fonte: Adaptado de STICKDORN e SCHNEIDER, 2014.

Estabelecidas as parcerias, deu-se início à retirada das bicicletas resgatadas do depósito da Universidade, as quais foram levadas à Bicicletaria Cultural para triagem e recuperação das bicicletas que tinham possibilidade de recuperação, uma vez que o longo período paradas e expostas a intempéries causou a deterioração de peças e até mesmo equipamentos inteiros. As bicicletas recuperadas e viabilizadas foram identificadas pela cor, marca, número de série, tipo e dimensão do quadro e descrição de componentes para controle do projeto.

O desenvolvimento do CoolabBici teve seu design centrado no usuário, com a elaboração de sistemas e processos tangíveis e intangíveis, gerando experiência. Para isso, foi necessária abertura para uma construção em rede, entre parceiros e com as pessoas que seriam usuárias do sistema. Conhecendo suas motivações e permitindo que participassem com contribuições por meio de propostas e sugestões, em um ambiente de co-criação, conforme preconizado por Stickdorn e Schneider (2014). O sistema de empréstimo teve direcionamento à comunidade interna devido às características dessa comunidade, composta majoritariamente por estudantes com potencial de se tornarem formadores de opinião e multiplicadores fora deste ambiente, estando inseridos em um contexto de constantes janelas de oportunidade ${ }^{2}$, marcadas pelos semestres letivos. Assim, definiu-se que os ciclos do projeto se inseririam nestas janelas, baseadas nos períodos letivos, primeiro semestre, segundo semestre e férias de verão.

${ }^{2}$ Refere-se ao intervalo de tempo subsequente a uma mudança de residência, trabalho ou outra mudança grande na vida - como o nascimento de um filho, por exemplo, no qual os hábitos ficariam enfraquecidos e que haveria uma potencialização na efetividade de ações ou programas para promoção a comportamentos mais sustentáveis. Esse intervalo poderia ser de até 12 meses após a mudança, mas os primeiros meses (entre dois e oito) deste período, teriam ainda maior potencial (THOMAS, POORTINGA, SAUTKINA, 2016) 
A primeira rodada de empréstimos e acompanhamento dos participantes, aconteceu no segundo semestre de 2017 e teve o objetivo de ser uma rodada piloto, para testar seu funcionamento.

Como o objetivo do sistema, em consonância ao do projeto, é o de sensibilizar para o uso da bicicleta, definiu-se que o público-alvo, além de membro da comunidade interna, deveria ser formado por pessoas sem experiência no uso da bicicleta como transporte, que chamamos ciclistas iniciantes. Isto porque, não se buscava simplesmente oferecer bicicletas emprestadas e sem acompanhamento, mas promover e incentivar o uso a um grupo de pessoas que, provavelmente, de outra forma, não faria uso da bicicleta. Como a capacidade de oferta é limitada, seria necessário identificar se o empréstimo de um equipamento, as orientações iniciais e durante o uso, e acompanhamento por meio de sondas culturais seria capaz de, num grupo que não tinha o hábito de usar a bicicleta, mudar comportamentos. Estabeleceu-se, então, um formulário de inscrição e interesse prévios, com perguntas direcionadoras de modo a selecionar participantes interessados que se enquadrem nos requisitos do projeto. Neste formulário são coletadas informações pessoais e de contato e, também, dados físicos (para melhor adequação das bicicletas disponíveis). Além disso, são perguntadas as motivações e intenções de uso da bicicleta a ser cedida pelo projeto e acerca da experiência prévia com o uso deste meio de transporte.

Após 3 anos de projeto, o formulário foi sendo adaptado, uma vez que algumas questões foram se tornando mais relevantes para a seleção dos participantes. As diferentes edições de empréstimo (semestral ou férias) também possuem critérios diferentes para a escolha de participantes. 0 empréstimo semestral, prioriza o atendimento de ciclistas iniciantes ou com pouca experiência no uso da bicicleta, já o empréstimo realizado no período das férias, prioriza participantes que irão passar a maior parte do período na cidade de Curitiba (buscando assegurar que as bicicletas não fiquem paradas). A divulgação de abertura das inscrições e das demais ações desenvolvidas pelo projeto é feita através de cartazes nos campi da UFPR em Curitiba e pelas redes sociais do projeto e do programa Ciclovida, além de canais de comunicação oficiais da instituição.

O período de inscrições costuma durar cerca de uma semana a 10 dias e após o encerramento, a seleção é realizada com base nos critérios descritos anteriormente e na disponibilidade de bicicletas conforme perfil das pessoas interessadas, suas preferências apontadas no formulário ou, ainda, suas características físicas. Esta tentativa de adequação da bicicleta às pessoas participantes busca proporcionar, dentro do possível com o uso de bicicletas compartilhadas, maior conforto e segurança no uso da bicicleta, que são aspectos determinantes para a adoção das mesmas e o seu uso frequente. 
Na primeira edição, iniciada em agosto de 2017, após selecionados os participantes, a sistematização da entrega e recolhimento das bicicletas era feita pela equipe do projeto de maneira individual, na segunda e terceira edições, com o aumento do número de bicicletas disponíveis no projeto, passou-se a realizar entregas e devoluções coletivas. A partir da quarta edição, que teve início no segundo semestre de 2018, com base em propostas de participantes e da própria equipe, estabeleceu-se uma estratégia de passagem coletiva na qual, no dia da entrega, a orientação inicial é feita em grupo e, ao final, o participante da edição anterior entrega a bicicleta que estava consigo para o próximo participante, que recebeu instruções naquele dia. Com isso, aumentamos o engajamento e o comprometimento das usuárias e usuários do CoolabBici com a manutenção e revisão das bicicletas utilizadas.

Para o acompanhamento dos participantes foi desenvolvida uma ferramenta de sonda cultural, buscando identificar especificidades das usuárias e usuários ao longo do período de adaptação e adoção de um novo comportamento sustentável, o uso da bicicleta. 0 desenvolvimento desta ferramenta também foi feito de maneira colaborativa, com uma oficina com ciclistas de diferentes níveis de experiência antes do primeiro período de empréstimo iniciar, para que houvesse diferentes visões e opiniões do que uma pessoa que usa a bicicleta como transporte vivencia ao se locomover pela cidade (PRADO, 2019). Nesta oficina foram utilizadas ferramentas do design thinking, como mapa mental, mapa de empatia e brainstorming. Conforme descrito por Zacar (2014), a sonda cultural é um método de acompanhamento menos invasivo e mais fiel ao acontecimento, no momento em que ele ocorre, permitindo captar a experiência/ideia/pensamento do usuário sem perder informações. Tal abordagem foi escolhida também pensando que o acompanhamento deveria ocorrer de forma que permitisse se moldar ao dia a dia de cada participante. Além disso, as sondas culturais também permitem que o usuário registre o que sente da forma que achar mais interessante, como foto, vídeo, gravação de áudio, ou um diário, por exemplo. Como resultado da oficina, foi criado uma personagem fictícia, nomeada Abbi, conforme Figura 2 (a seguir). A proposta da existência da personagem é ter "alguém" que acompanhe as/os ciclistas iniciantes interagindo, apresentando sugestões, questionamentos sobre como está a experiência etc. A forma de interação, inicialmente, também era individual, por meio de aplicativo de mensagens instantâneas. Posteriormente com a percepção da necessidade de integrar os participantes, para que pudessem encorajar uns aos outros, essa interação passou a ser coletiva, via grupo de aplicativo e, também individual por meio de um diário personalizado, que continha páginas em branco e páginas com perguntas específicas a serem respondidas sobre o período de empréstimo. Esta mudança permitiu que os participantes compartilharem suas experiências e dúvidas, além de criar suas próprias narrativas do uso da 
bicicleta, definindo o que desejam mostrar e a forma de estruturar os dados apresentados. Esta ferramenta coletiva de acompanhamento foi classificada, por suas características, como Etnografia Móvel do modo como apresentado por Stickdor e Schneider (2014).

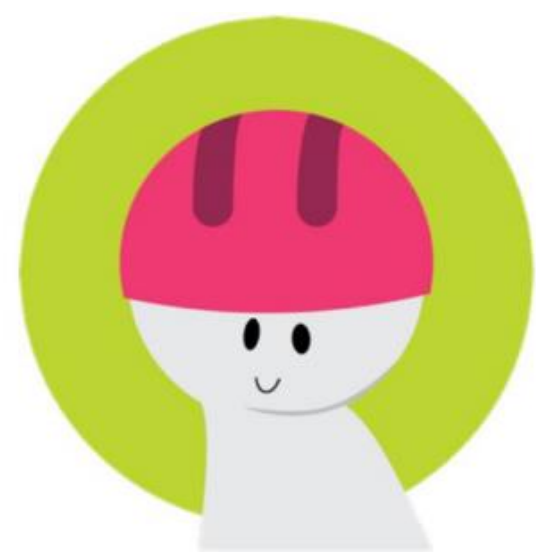

Figura 2: Personagem Abbi - Sonda Cultural Fonte: Elaboração própria (2017)

Próximo ao encerramento do período de empréstimo, os participantes são orientados a fazer a revisão da bicicleta antes da devolução/passagem, com eventual substituição de peças desgastadas pelo uso, como pastilhas de freio, cabos, pneus, etc., uma vez que o projeto não possui, atualmente, nenhuma forma de financiamento ou recursos para tais reparos. Essa proposta da revisão da bicicleta pelos participantes, também reforça o caráter colaborativo do sistema, mantendo os equipamentos sempre em condições de uso. No dia da devolução/passagem da bicicleta, solicitamos aos participantes que respondam um questionário final sobre a experiência ao utilizar a bicicleta nos últimos meses.

Em todas as edições de empréstimo do Coolabbici, tanto no período semestral quanto no de férias, as participantes selecionadas recebem - antes de ter acesso à bicicleta - instruções iniciais sobre como funciona o sistema colaborativo, dicas de segurança no trânsito e como utilizar a bicicleta como meio de transporte. Também recebem um Guia do Ciclista, material impresso desenvolvido pelo programa Ciclovida, um exemplar de um compilado do Código de Trânsito Brasileiro para ciclistas, impresso desenvolvido pelo DETRAN-PR e uma faixa refletiva (que pode ser usada também para prender a barra da calça e evitar que enrosque na coroa da bicicleta). Nesse momento, os participantes assinam os termos legais, entre eles, o termo de consentimento livre e esclarecido, para que os dados do projeto possam ser utilizados em pesquisas e artigos acadêmicos, a declaração de ser maior de idade e o termo de responsabilidade para com a bicicleta, que contém dados de identificação das mesmas. Além da passagem de bicicletas entre os 
participantes como forma de criar uma conexão entre participantes e com as bicicletas, que receberam nomes ao invés de números. Foram escolhidos nomes de doces que permitiram a criação de adesivos personalizados com Abbi utilizando um capacete correspondente ao nome da bicicleta, além de adesivos de identificação do sistema e um spoke card na roda dianteira com seu nome, número e um QR code direcionando para a página do projeto no Facebook. Toda essa identificação também permite que as bicicletas sejam reconhecidas como parte do sistema de empréstimo CoolabBici nas ruas, além de funcionar como forma de divulgação do projeto e de autorreconhecimento entre as pessoas participantes.

Na próxima seção, apresentaremos os resultados do sistema de empréstimo, desenvolvido e executado pelo projeto de extensão 'Sensibilização para o Uso da Bicicleta como Modal de Transporte pela Comunidade UFPR' desde o início da operação, no segundo semestre de 2017 até o empréstimo de férias de 2019-2020, totalizando 8 (oito) edições. Este período foi escolhido devido ao acesso completo aos dados, uma vez que o empréstimo do primeiro semestre de 2020, que deveria ter sido encerrado em agosto deste ano, foi prorrogado devido à pandemia da COVID19.

\section{Resultados e discussão}

O projeto de extensão teve início em maio de 2017 e, o sistema de empréstimo por ele desenvolvido começou a ser realizado em agosto de 2017. Desde então, até março de 2020, quando encerrou o empréstimo de férias de 2019-2020 - sendo 5 semestres letivos e 3 períodos de férias de verão. Ao longo dessas 8 edições houve 211 inscrições de pessoas interessadas em emprestar uma bicicleta, sendo os períodos letivos responsáveis por $77 \%$ das inscrições. Esse dado, ressalta a importância da janela de oportunidade para mudança de hábitos mencionada anteriormente, já que no início dos semestres letivos as pessoas se sentem mais motivadas a experimentar mudanças em suas rotinas diárias.

O principal modal utilizado pelas pessoas que se inscreveram para participar do projeto naquele período era o ônibus, representando $61 \%$ dos usuários. Os deslocamentos a pé somaram $32 \%$ das respostas e, em automóvel (próprio ou carona ${ }^{3}$ ) e moto, 6\%. Apesar do projeto focar na mudança de modal do veículo motorizado individual para a bicicleta tradicional (propulsão humana), o processo de seleção não exclui participantes que não estão nessa categoria, já que o

${ }^{3} \mathrm{O}$ item carona aqui se refere ao uso de transporte de passageiros em veículo de aluguel, como Táxi, Uber, etc; ou carona com familiares, amigos ou colegas. 
projeto visa pela sensibilização não somente da/o participante que for selecionada/o, mas também das pessoas em seu entorno, como familiares e amigas.

0 projeto é aberto à toda comunidade interna da Universidade, independentemente do tipo de vínculo, estudantes, docentes, técnicos-administrativos e terceirizados, mas o perfil dos interessados se concentra majoritariamente entre estudantes. A faixa etária dos 18 aos 30 anos corresponde a $89 \%$, sendo que a maioria, $65 \%$, identifica-se como sendo do gênero feminino.

As pessoas interessadas relataram como motivos para ainda não utilizar a bicicleta como transporte a sensação de insegurança no trânsito e a falta de dinheiro para aquisição de uma bicicleta. Ainda, quando questionadas sobre suas motivações a participar, a baixa qualidade do transporte público, a oportunidade de experienciar a o uso da bicicleta antes de comprar uma, a busca por mais facilidade e autonomia no transporte e a preocupação com a saúde foram as mais mencionadas.

Até a 8a. edição, que foi o empréstimo de férias 2019/2020, foram realizados 77 empréstimos e, durante todo o período de participação, procuramos verificar a efetiva adoção da bicicleta como principal meio de transporte, estabelecendo em todos os ciclos do projeto um aperfeiçoamento de sua estrutura inicial, realizado a partir de ferramentas do Design Thinking de Serviços.

Entre as formas de aperfeiçoamento, está a análise dos dados coletados a partir das ferramentas sonda cultural e etnografia móvel, desenhadas para se adequar ao contexto do CoolabBici. A partir das respostas obtidas foi possível dividir os dados em duas grandes categorias de relatos: Externos e Internos. Os relatos externos referem-se às condições da cidade, estrutura, custo, segurança, trajetos e intempéries que podem influenciar ao uso da bicicleta. Na maioria deles, o projeto tem pouca ou nenhuma ingerência, ainda que seus resultados possam oferecer suporte a tomadores de decisão e criações de políticas públicas. Apenas nos aspectos de trajeto e intempéries o projeto consegue atuar mais diretamente. No primeiro, indicando rotas mais seguras (do ponto de vista de trânsito e de segurança pública, explicitando como identificar tais rotas e, ainda, oferecendo a possibilidade de contatar a ONG Bike Anjo para suporte quanto a esta questão). No segundo, passando orientações e dicas de como aproveitar melhor a bicicleta tanto nos dias de bastante frio, muito calor ou chuva. Já os aspectos internos estão ligados a sensações e sentimentos experienciados pelas/os participantes e, mais frequentemente, fazem parte dos aspectos que o projeto procura oferecer suporte aumentando a confiança das/dos participantes.

Em ambas as categorias, de aspectos Internos e Externos, foi possível perceber que os participantes utilizaram a etnografia móvel (que era feita via grupo de mensagens instantâneas pelo celular) mais para relatos positivos, contando acontecimentos de suas pedaladas e motivando 
uns aos outros e, na sonda cultural, de preenchimento individual, descreveram as experiências nem sempre positivas, desafios e dificuldades.

Ao final de cada período de empréstimo, solicita-se que os participantes respondam a um questionário por meio da plataforma Google Forms. Deste questionário, foram obtidas 45 respostas e a primeira aplicação foi feita na devolução das férias de verão 2017/2018. 0 menor número de respostas em relação ao número de empréstimos se deve ao fato de que, até o empréstimo do segundo semestre de 2018 o questionário era enviado posteriormente ao e-mail das/os participantes e, nem sempre, obtinham-se as respostas. A partir do segundo semestre de 2018, adotou-se a aplicação do questionário no dia da devolução/passagem da bicicleta, motivo pelo qual o índice de respostas passou a ser de $100 \%$.

Entre as perguntas feitas há uma sobre se conseguiram utilizar a bicicleta tanto quanto esperavam: 61\% afirmaram que sim e 39\% disseram que não. Aos que responderam negativamente, pergunta-se o motivo, sendo o modelo da bicicleta (40\%), a dificuldade em implementá-la em sua rotina (40\%) e a falta de condicionamento físico (20\%), os mais comuns.

No questionário final, também é investigada a ocorrência de situações ou experiências negativas durante o uso da bicicleta. Do total, $71 \%$ das pessoas participantes relataram ter tido algum tipo de experiência negativa, sendo a falta de respeito no trânsito a mais frequente com $34 \%$ das respostas. Além disso, 14\% também descrevem problemas com a bicicleta (ex.: pneu furado) e as mudanças climáticas (ex.: ter pegado chuva) como negativas. A infraestrutura urbana insuficiente é outro relato presente nas respostas, sendo que $12 \%$ relatam a falta de locais próprios para bicicleta, e ciclovias e ruas danificadas, impossibilitando ou dificultando a utilização, conforme apresentado na Figura 3 (a seguir). 


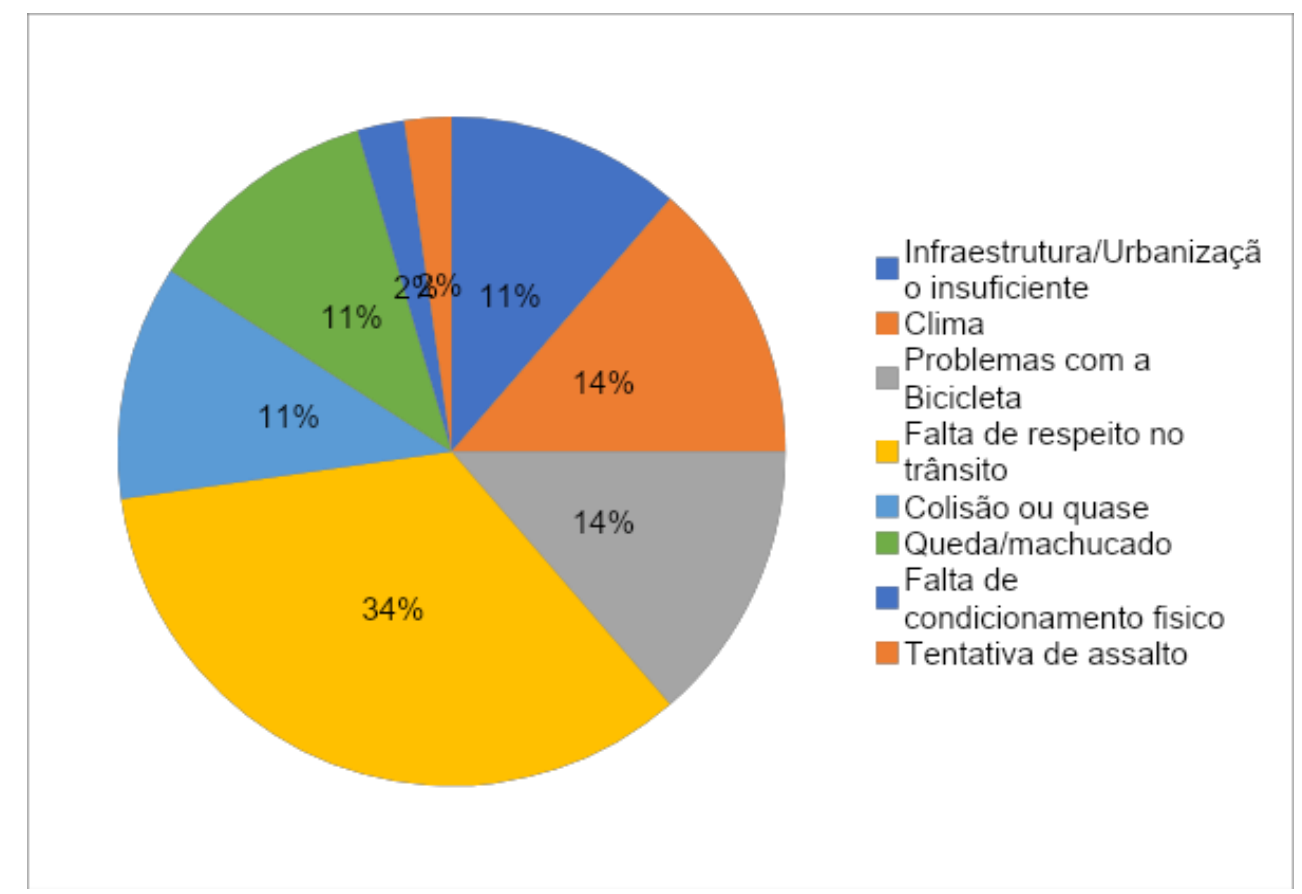

Figura 3: Principais características presentes nos relatos negativos dos participantes Fonte: Elaboração própria (2020)

Apesar das dificuldades mencionadas, $78 \%$ declararam não ter diminuído o uso da bicicleta, relatando que as ferramentas de etnografia móvel e sonda cultural os ajudaram a manter a motivação para continuar. Analisando as respostas de todos as/os respondentes do questionário, 93\% declarou que o desejo de adquirir uma bicicleta própria após o empréstimo aumentou e, 7\% que a vontade permaneceu a mesmo. Não houve nenhuma resposta indicando que a vontade diminuiu. É possível relacionar estes números positivos, às experiências com a bicicleta na cidade, e que, apesar das desventuras eventualmente experienciadas, a sensação de pertencimento à cidade nos trajetos e a interação social entre ciclistas ocasionaram um impacto positivo nas rotinas das/os participantes, percebendo muitas vezes despender menos tempo de deslocamento e estar mais disposto fisicamente e emocionalmente.

“(...) Ver a cidade de uma forma diferente, ter mais calma ao me deslocar rotineiramente, perceber como o tempo passa diferente quando se está com algo que depende só da sua motivação e energia, mas principalmente o controle da minha ansiedade, isso foi muito importante para mim." (Relato da Experiência no Projeto v.02.2018, Coolabbici, 2018.)

As inseguranças relatadas que impossibilitavam a utilização da bicicleta como modal antes da participação se apresentam em maior parte como receios superados por $90 \%$ das/os respondentes. Sendo que o principal empecilho era o medo e insegurança de utilizar a bicicleta 
nas ruas, dividindo espaço com veículos automotores. Esse medo, por vezes, também é da família ou pessoas próximas à pessoa que se inscreve para participar. No entanto, após período de adaptação, há relatos de sensibilização nos quais estas mesmas pessoas, que tinham receio, passam a ser incentivadores, conforme relatado por uma outra participante do gênero feminino:

"Minha mãe ficou completamente assustada e insegura, mas depois viu que eu fiquei tão feliz e me adaptei tão bem que me ajudou a comprar uma agora que o projeto acabou." (Relato da Experiência no Projeto v.02.2018, Coolabbici, 2018).

Outros participantes também relatam as experiências positivas que tiveram com os familiares e amigos sobre a participação no projeto, da possibilidade de empréstimo e de certa forma, de ter um grupo de apoio, para poder usar a bicicleta com mais segurança no trânsito. Relatando também a sensibilização com o modal por parte de conhecidos em sua volta, se sentindo motivados a participar, adquirir uma bicicleta para pedalar junto ou mesmo perceber outros ciclistas presentes na cidade e a preocupação com a segurança deles.

Ainda sobre a pós-participação no projeto, ao final de algumas edições, foi solicitado que as/os participantes descrevessem em três palavras suas percepções e experiências no período de uso da bicicleta por meio de um sistema de nuvem de palavras online. Todas as nuvens obtidas continham majoritariamente palavras positivas. Abaixo, na Figura 4 (a seguir) um dos resultados obtidos.

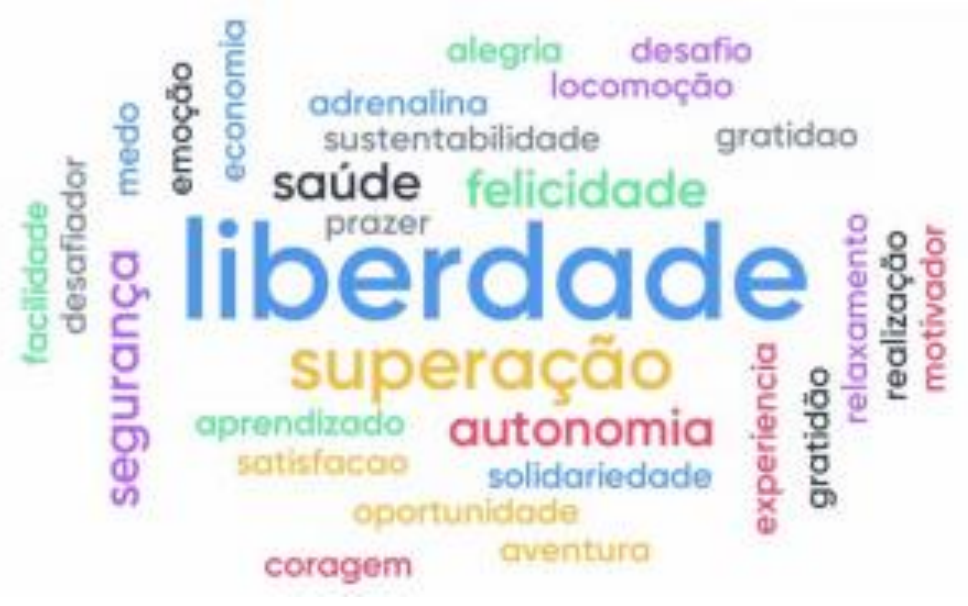

Figura 4: Nuvem de palavras participantes

Fonte: Gheysa Caroline Prado, Kamila Elisabeth do Espírito Santo Almeida Coelho da Cruz, Marina Caus dos Santos, Carolina Teixeira dos Santos, Letícia Zem Messias

A sensação de liberdade, principal palavra presente na nuvem, seguida de superação, autonomia e saúde, também aparece nos relatos descritos nas considerações dos participantes 
sobre toda a sua experiência no projeto, como manifesta um dos participantes do gênero masculino:

\begin{abstract}
"Rompendo minhas expectativas, a bicicleta foi muito mais do que uma experiência de autoconhecimento físico-corporal sobre duas rodas, foi uma experiência físico-espacial dentro do espaço urbano e uma experiência físicosocial dentro das relações humanas, sendo o trânsito uma delas. Deixar de ser um agente passivo no trânsito, dentro de um biarticulado, para ser um agente ativo, que ocupa e que incomoda, fez reconhecer a bicicleta não mais como um agente neutro dentro da cidade. Reconhecer o medo do pedestre ao ver uma bicicleta vindo em sua direção me fez perceber o quanto a bicicleta, até então inofensiva no meu imaginário, pode se tornar um instrumento de opressão assim como as modalidades automotivas. Reconhecer o incômodo dos motoristas ao ver uma bicicleta ocupando parcialmente sua faixa obrigando-os a reduzir a velocidade me fez constatar que a bicicleta de neutralidade nada tem. Escolher entre atravessar um trecho pela calçada ou pela rua, ao meu ver, é uma postura política. Conceber como seguir a lógica da opressão, tão reproduzida na sociedade, ou se impor contra ela acontece pelo posicionamento geográfico da bicicleta é algo fascinante. Até então, para mim, a postura política da bicicleta se limitava em apenas utilizá-la como modalidade de transporte alternativo à modalidade insustentável e individualista que é o automóvel particular, e não considerava a maneira com que ela é utilizada." (\#Ferias2017/2018-Relato da Experiência no Projeto, Coolabbici, 2018).
\end{abstract}

Após alguns semestres de funcionamento do sistema, entramos em contato com 32 dos exparticipantes - total de participantes até o segundo semestre de 2018 - para analisar a continuidade do uso da bicicleta e, conforme mostrado na Tabela 1, foram obtidas 22 respostas e 8 pessoas afirmaram seguir utilizando a bicicleta como meio de transporte frequentemente. 
Revista Experiência, Santa Maria, UFSM, Vol. 6, N. 02

\begin{tabular}{|c|c|c|c|c|}
\hline Particlpante & $\begin{array}{l}\text { Uso durante a } \\
\text { particlpaçjo }\end{array}$ & $\begin{array}{l}\text { Vontade de ter } \\
\text { uma bickleta }\end{array}$ & $\begin{array}{l}\text { Continuou usando } \\
\text { depols (fev/2019) }\end{array}$ & Justificativa \\
\hline Participante I & sim & ficou igual & $\operatorname{sim}$ & Comprou nova \\
\hline Participante 2 & $\mathrm{~N} 30$ & Aumentou & Eventwaimente & Sem recurso para aquisk 30 \\
\hline Participante 3 & Parcialmente & Aumentou & & \\
\hline Participante 4 & $\operatorname{sim}$ & Aumentou & $\sin$ & Alugada \\
\hline Particlpantes & $\operatorname{sim}$ & Aumentou & Eventualmente & Sem recurso para aquilik 30 \\
\hline Participante 6 & Parcialmente & Aumentou & & \\
\hline Participante 7 & Sim & Aumentou & & \\
\hline Partcipante 8 & Sim & Aumentou & & \\
\hline Particlpante 9 &. & $\cdot$ & & \\
\hline Particlpante 10 & Sim & Aumentou & Eventualmente & Sem recurso para aquiskso \\
\hline Particlpante ni & Sim & Aumentou & Eventualmente & Sem recurso para aquiskjo \\
\hline Participante 12 & - & Aumentou & NSO & Ja nso tinha usado amtes \\
\hline Participante 13 & $\operatorname{Sim}$ & Aumentou & & \\
\hline Particlpante 44 & NSO & - & $\mathrm{NSO}$ & Js nSo tinha usado antes \\
\hline Particlpante ss &. & . & & \\
\hline Participante $\$ 5$ & Sim & Aumentou & & \\
\hline Particlpante 17 & $\operatorname{sim}$ & Aumentou & Eventualmente & Sem recurso para aquisisJo \\
\hline Particlpante is & Sim & Aumentou & Sim & Emprestada \\
\hline Particlpante 19 & Pardalmente & Aumentou & $\operatorname{sim}$ & Comprou nova \\
\hline Particlpante zo & Sim & Aumentou & NSo & Sem recurso para aquils so \\
\hline Particlpante at & NSD & - & & \\
\hline Particlpante 22 & Pardalmente & Aumentou & & \\
\hline Participante 23 & Sim & Aumentou & Sim & Comprou nova \\
\hline Particlpante 24 & 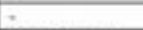 & $+\quad$ & NSO & Sem recurso para aqulsiga \\
\hline Participante 25 & Pardialmente & Fikou iqual & & \\
\hline Participante 26 & NSo & Ficoulgual & NSo & Ja nSo tinha usado antes \\
\hline Participante 27 & $\sin$ & Aumentou & Sim & Comprou usada \\
\hline Particlpante 28 & $\mathrm{Sim}$ & Aumentou & Sim & Emprestada \\
\hline Participante ag & Sim & Aumentou & & \\
\hline Particlpante 30 & Sim & Aumentou & Sim & Comprou usads \\
\hline Participante 31 & NSSo & Aumentou & Eventualmente & NSo encaixa na rotina atual \\
\hline Participante 32 & Sim & Aumentou & & \\
\hline
\end{tabular}

Quadro 1: Verificação da adoção da bicicleta

Fonte: Gheysa Caroline Prado, Kamila Elisabeth do Espírito Santo Almeida Coelho da Cruz, Marina Caus dos Santos, Carolina Teixeira dos Santos, Letícia Zem Messias

Dentre os respondentes que não continuaram e ou que apenas usam eventualmente, o principal motivo apontado para a não continuidade é devido à falta de recurso financeiro para aquisição de uma, motivo que já se mostrava presente no interesse de participação do projeto.

Pode-se, portanto, verificar que existem evidências de que as pessoas que participaram do CoolabBici - sistema de empréstimo de bicicletas - alcançaram, em certa medida, uma mudança de hábitos relacionada à sua forma de deslocamento, com efetiva adoção da bicicleta por parte das pessoas, além da sensibilização quanto a esse meio de transporte na cidade. Deste modo, percebese que o projeto vem atingindo seus objetivos, de sensibilizar para o uso deste modal como transporte, não apenas seus participantes diretos, mas também seus entornos.

\section{Conclusão}

O presente artigo buscou apresentar a criação, funcionamento e resultados de uma ação do projeto de extensão Sensibilização para o Uso da Bicicleta como Modal de Transporte na Comunidade UFPR. Foi apresentado também, um panorama nacional e local do contexto de surgimento e atuação do projeto ao qual a ação é vinculada evidenciando a problemática da 
mobilidade urbana bem como do papel da extensão universitária e do design na possibilidade de promover a mudança de hábitos a partir de ações de incentivo e acompanhamento de participantes dessas ações.

No decorrer do texto, foram apresentadas e descritas as estratégias utilizadas pelo projeto para promoção do uso da bicicleta como modal de transporte na comunidade UFPR. Como resultado das aplicações percebemos que o sistema colaborativo proposto, o CoolabBici, tem se mostrado satisfatório, com números relevantes de continuidade do uso do modal após o encerramento da participação. Além disso, percebemos também a eficácia quanto ao funcionamento das ferramentas utilizadas para manter o interesse das/os participantes e trazer segurança de que suas dúvidas poderiam ser sanadas a qualquer momento, o que incentivava a manter o contato.

Os dados e resultados obtidos se mostraram bastante adequados, uma vez que os sujeitos pesquisados se tornam também sujeitos ativos na produção de dados e alterações propostas ao sistema, ao responderem os formulários, preencherem a sonda cultural e participarem ativamente da etnografia móvel. Busca-se, a partir destes dados, melhorar o funcionamento do sistema e possivelmente também de sua efetividade no processo de sensibilização para o uso da bicicleta como modal de transporte.

O projeto continua em andamento, bem como a ação CoolabBici e, neste ano de 2020 as bicicletas seguem emprestadas para um novo grupo de participantes e as demais atividades, dentro do possível, estão sendo realizadas online. Com a pandemia, a 9ạ. edição do CoolabBici iniciada em março de 2020 permanece vigente, já que o período de passagem, previsto para ocorrer em agosto de 2020 foi concomitante a um momento de pico de infecções na cidade de Curitiba.

\section{Referências}

Departamento Nacional de Trânsito (DENATRAN). Manual de procedimentos para o tratamento de polos geradores de tráfego. Brasília: DENATRAN/FGV, 2001. Disponível em: <http://www.capacidades.gov.br/biblioteca/detalhar/id/121/titulo/manual-deprocedimentos-para-o-tratamento-de-polos-geradores-de-trafego $>$. Acesso em: 06 de outubro de 2020.

DOS SANTOS, M. C., PIOVEZANI, T. M., DE SOUZA, M., FALKIEWICZ, F. R. C., SCHAFASCHEK, M. C. I., PRADO, C. G., NETO, F. V. V., FONSECA, K. F. O., BELOTTO, J. C. A. \& NAKAMORI, S. (2018) Coolabbici: Projeto de extensão para recuperação e empréstimo de bicicletas na comunidade UFPR. Anais do 8o. Congresso Brasileiro de Extensão Universitária - Natal RN. 
Instituto Brasileiro de Geografia e Estatística. (2019). Curitiba: População estimada. Disponível em: <https://www.ibge.gov.br/cidades-e-estados/pr/curitiba.html>. Acesso em: 07 de outubro de 2020.

Instituto de Pesquisa e Planejamento Urbano de Curitiba. (2017). Apresentação dos resultados da pesquisa origem destino: Distribuição modal. Disponível em: $<$ https://ippuc.org.br/visualizar.php?doc=http://admsite2013.ippuc.org.br/arquivos/documen tos/D536/D536 017 BR.pdf > . Acesso em: 07 de outubro de 2020.

ITDP - Instituto de Políticas de Transporte e Desenvolvimento. (2019). Boletim 1: Mobilidade de baixo carbono. Disponível em: < http://itdpbrasil.org/wp-

content/uploads/2019/02/MobiliDADOS Boletim1.pdf >. Acesso em: 06 de outubro de 2020.

ITDP - Instituto de Políticas de Transporte e Desenvolvimento. (2016). Há espaço para mais carros? A dura batalha por uma cidade limpa, segura e com o espaço distribuído de forma justa. Disponível em: <https://itdpbrasil.org.br/ha-espaco-para-mais-carros/>. Acesso em: -7 de outubro de 2020.

Ministério das Cidades (2017). Caderno técnico para projetos de mobilidade urbana: Transporte ativo. Disponível em:

$<$ https://antigo.mdr.gov.br/images/stories/ArquivosSEMOB/Biblioteca/Criterios transporte.p df>. Acesso em: 06 de outubro de 2020.

Reck Neto, I. (2018). Uma análise do consumo de energia na mobilidade urbana de Curitiba. Disponível em: < $\underline{\text { https://www.mobilize.org.br/midias/pesquisas/uma-analise-do-gasto-de- }}$ energia-na-mobilidade.pdf $>$. Acesso em: 06 de outubro de 2020.

OPAS - Organização Pan-Americana de Saúde Brasil. (2019). Folha informativa - Acidentes de trânsito. Disponível em:

$<$ https://www.paho.org/bra/index.php?option=com content\&view=article\&id=5147:acidentesde-transito-folha-informativa\&Itemid=779> . Acesso em: 07 de outubro de 2020.

PRADO, Gheysa Caroline. (2019). Modelo para promoção da mobilidade urbana ativa por bicicleta : uma abordagem do design de serviço para o comportamento sustentável (Tese de doutorado). Universidade Federal do Paraná - UFPR, Curitiba, PR, Brasil. Disponível em: < https://hdl.handle.net/1884/61906>. Acesso em: 06 de outubro de 2020.

Ramalho, G. (2018). Brasil perde R \$ 267 bilhões por ano com congestionamentos. Disponível em: <https://g1.globo.com/globonews/noticia/2018/08/07/brasil-perde-r-267-bi-por-anocom-congestionamentos.ghtml >. Acesso em: 08 de outubro de 2020.

Salles, J. (2010). ONU elegeu a bicicleta como o transporte ecologicamente mais sustentável do planeta. Disponível em:

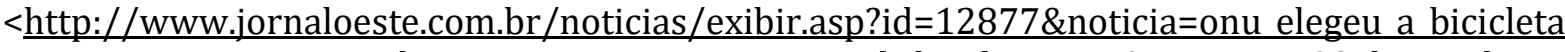
como o transporte ecologicamente mais sustentavel do planeta>. Acesso em: 08 de outubro de 2020 .

STICKDORN, M; SCHNEIDER, J. (Orgs.). Isto é design thinking de serviços : fundamentos, ferramentas, casos. Porto Alegre: Bookman, 2014.

TANG, T.; BHAMRA, T. Putting consumers first in design for sustainable behaviour: A case 
study of reducing environmental impacts of cold appliance use. International Journal of Sustainable Engineering, v. 5, n. 4, p. 37-41, 2012.

THOMAS, G. O.; POORTINGA, W.; SAUTKINA, E. Habit discontinuity, self-activation, and the diminishing influence of context change: Evidence from the UK Understanding Society survey. PLoS ONE, v. 11, n. 4, p. 1-16, 2016.

UNIVERSIDADE FEDERAL DO PARANÁ (UFPR). Pesquisa da Mobilidade Universitária em Curitiba. Junho 2016. Curitiba, 2016. [não publicado].

VIAS SEGURAS. Estatísticas nacionais de acidentes de trânsito. (2020). Disponível em: <http://www.vias-seguras.com/os acidentes/estatisticas/estatisticas nacionais >. Acesso em: 03 de novembro de 2020.

ZACAR, Cláudia Regina Hasegawa. 0 uso de sondas culturais no processo de design de produto: uma experiência com estudantes de graduação. In: 11. Congresso Brasileiro de Pesquisa e Desenvolvimento em Design. 2014. 
CoolabBici: support system for raising awareness and promoting the use of bicycles as transport.

\begin{abstract}
The extension project 'Awareness of the Use of Bicycles as a Mode of Transport by the UFPR Community' aims to support change of commute habit inside and outside UFPR community offering some incentive for the bicycle use. To achieve the goal the project promotes a variety of educational and interactional activities in the community and its responsible for the creation of a bicycle sharing system using recovered bicycles, the CoolabBici. This article aims to present and detail the creation and operation process of CoolabBici, which was developed using Service Design Thinking principles. The results point out that the system operates adequately, and it has potential to be expanded and replicated.
\end{abstract}

\section{Keywords}

Urban mobility; design thinking; bicycle
CoolabBici: sistema de apoyo a la sensibilización y promoción del uso de la bicicleta como transporte.

\section{Resumen}

El proyecto de extensión 'Sensibilización sobre el uso de bicicletas como medio de transporte por la comunidad de la UFPR' busca promover un cambio de hábitos en la comunidad interna y externa de la UFPR fomentando el uso de la bicicleta como medio de transporte. Para ello, el proyecto lleva a cabo varias acciones educativas y de interacción con la comunidad y se encarga de crear un sistema de intercambio de bicicletas recuperadas, CoolabBici. Este artículo tiene como objetivo presentar y detallar el proceso de creación y funcionamiento de CoolabBici, que se desarrolló utilizando los principios de Service Design Thinking. Los resultados apuntan al correcto funcionamiento del sistema $\mathrm{y}$ el potencial de replicación y expansión.

\section{Palabras clave}

Mobilidad urbana; design thinking; bicicleta 